\title{
Clinical Features and Management Outcomes of Severe Hand, Foot and Mouth Disease
}

\author{
Hui Tian ${ }^{a}$ Qiao-Zhi Yang ${ }^{b}$ Jun Liang ${ }^{b}$ Sheng-Ying Dong ${ }^{b}$ Zhi-Jun Liu ${ }^{a}$ \\ Le-Xin Wang ${ }^{c}$ \\ Departments of ${ }^{a}$ Intensive Care and ${ }^{b}$ Pediatrics, Liaocheng People's Hospital and Liaocheng Clinical School of \\ Taishan Medical University, Liaocheng, PR China; ' School of Biomedical Sciences, Charles Sturt University, \\ Wagga Wagga, N.S.W., Australia
}

\section{Key Words}

Hand, foot and mouth disease $\cdot$ Enterovirus $71 \cdot$ Mechanical ventilation - Mortality

\begin{abstract}
Objective: This study was designed to describe the clinical features and management outcomes of severe hand, foot and mouth disease (HFMD). Subjects and Methods: Data on 147 severe HFMD patients during an outbreak in 2009 were analyzed. Results: Most patients were under 3 years of age; $102(69.4 \%)$ were boys. All had skin rashes and fever of $\geq 38^{\circ} \mathrm{C}$. All $(n=147,100 \%)$ showed signs of central nervous system involvement, such as lethargy $(n=124,84.4 \%)$, myoclonic jerks ( $n=76,51.7 \%)$, or drowsiness ( $n=34,23.1 \%)$. Respiratory symptoms were mainly tachypnea $(n=112,76.2 \%)$ or bradypnea ( $n=21,14.3 \%)$. Common cardiovascular symptoms included tachycardia $(n=134,91.2 \%)$ and hypertension $(n=23,15.5 \%)$. Chest $X$-ray showed increased markings in 76 (51.7\%) or consolidation in 44 (29.9\%). Hyperglycemia and elevated blood lactic acid levels were found in 127 (86.4\%) and 130 (88.4\%), respectively. Positive enterovirus EV71-PCR was found in $113(76.9 \%)$. All patients were treated with mechanical ventilation for $61.2 \pm 12.8 \mathrm{~h}$ (range, $40-96 \mathrm{~h}$ ), as well
\end{abstract}

as mannitol, dexamethasone, gamma globulin and ribavirin. Dopamine, dobutamine or amrinone was administered in $58.5,51.0$ and $21.8 \%$, respectively. Three patients (2\%) died during hospitalization. All others had a full recovery and were discharged after 14.2 \pm 1.6 days (range, 12-17 days). Conclusion: Central nervous and cardiorespiratory systems were involved in the patients with severe HFMD. Fasting blood glucose and lactic acid levels increased in the majority of patients. Mechanical ventilation and supportive pharmacotherapy were associated with a good clinical outcome in these patients.

Copyright $\odot 2011$ S. Karger AG, Basel

\section{Introduction}

Hand, foot and mouth disease (HFMD) is a communicable disease that mainly affects children. It is frequently associated with enterovirus EV71 and its main clinical features include rashes in hand, foot, or mouth, aseptic meningitis, poliomyelitis-like acute flaccid paralysis, brainstem encephalitis, and other severe systemic disorders, such as pulmonary edema and cardiorespiratory collapse [1]. Large outbreaks of HFMD were first re-

\section{KARGER \\ Fax +4161306 1234 \\ E-Mail karger@karger.ch}

www.karger.com (c) 2011 S. Karger AG, Basel

1011-7571/12/0214-0355\$38.00/0

Accessible online at:

www.karger.com/mpp
Prof. Le-Xin Wang

School of Biomedical Sciences

Charles Sturt University

Wagga Wagga, NSW 2678 (Australia)

Tel.+61 26933 2905, E-Mail lwang@csu.edu.au 
ported in Malaysia and Taiwan between 1997 and 1998 [2-4], and regular epidemics have since been reported in countries across the Asia-Pacific region, in particular in China [5]. Cases of HFMD have also been identified in some European countries and in some of the epidemics coxsackieviruses A6 and A10 were also involved [6, 7]. The HFMD is considered a self-limiting illness and most children who present with aseptic meningitis generally have good outcomes [1]. However, a small proportion can rapidly develop neurological and systemic complications that can be fatal $[5,8]$. In this report, we describe the clinical characteristics and management outcomes of patients with severe HFMD from an inland community in China.

\section{Subjects and Methods}

\section{Patient Selection}

This study was approved by the Institution Review Board of Liaocheng People's Hospital. As this was a retrospective analysis of de-identified patient data, no written informed consent was required. Liaocheng People's Hospital is a 2,600-bed tertiary teaching hospital in west Shandong Province, providing services to approximately 5.6 million people, mostly residing in rural and regional centers or townships. The hospital is the only designated referral center for HFMD in the region, and all identified HFMD cases are required to be hospitalized and managed by a specially equipped pediatrics unit in the hospital. Between January and June 2009, 15,823 patients with a clinical diagnosis of HFMD were admitted to the hospital for treatment. Of the 15,823 patients, 147 $(0.9 \%)$ were severely ill, requiring mechanical ventilation. The clinical characteristics and the outcomes of the 147 patients were subsequently analyzed.

The initial diagnosis of HFMD was based on the criteria in the Prevention and Control Guidelines for HFMD, and Diagnosis and Treatment Guidelines for human enterovirus EV71, published by the Chinese Ministry of Health in 2008 [9, 10]. Mild HFMD was defined as the presence of fever and vesicular lesions on palms, feet and mouth. Patients' clinical manifestations such as fever, rashes on the hands, foot and mouth, and other symptoms such lethargy or myoclonic jerks were often the first signs of HFMD. Subsequent virological tests were performed by examining throat and rectal swabs for positive enterovirus EV71 nucleic acid. Severe HFMD was defined as any one of the following findings in a patient: (a) symptoms of central nervous system involvement, such as lethargy, myoclonic jerks, drowsiness, unconsciousness, muscle spasm or rigidity, acute flaccid paralysis, or cerebellar ataxia; (b) respiratory dysfunction, such as tachypnea, bradypnea, or irregular respiration rhythm, and reduction in oxygen saturation levels, and (c) cardiovascular dysfunction, such as hypertension or hypotension, tachycardia or bradycardia, cold extremities, or piebald skin.

The age-specific definitions of respiratory and cardiovascular dysfunction were based on deviations from the normal vital signs that are readily available in the public domain [11].

\section{Mechanical Ventilation}

The indications for initiating mechanical ventilations for these patients with HFMD were central nervous system involvement, increased blood level of lactic acid, hyperglycemia or hypoglycemia. In addition, patients must have signs of cardiovascular dysfunction or respiratory dysfunction.

All patients were sedated by intravenous infusion of midazolam (0.1-0.2 mg/kg per hour). The respiration rate was set at 26$30 / \mathrm{min}$, and positive end-expiratory pressure was set at $8-14 \mathrm{~cm}$ $\mathrm{H}_{2} \mathrm{O}$. Arterial oxygen saturation rate was constantly monitored and the ventilation parameters were adjusted according to the oxygen saturation results.

Indications for withdrawing mechanical ventilation were all of the following: (a) when the ventilation was changed to continuous positive airway pressure mode, patient's spontaneous respiration rate was maintained between 20 and 30 breaths/min, achieving spontaneous breathing tidal volume of 6-8 $\mathrm{ml} / \mathrm{kg}$; (b) normal and stable blood pressure and heart rate with warm extremities and no piebald skin; significant improvement in chest X-ray; normalization of blood sugar and lactic acid levels $(<2.2 \mathrm{mmol} / \mathrm{l})$, and (c) absence of myoclonic jerks after cessation of intravenous midazolam.

\section{Other Supportive Treatment}

To reduce the increased intracranial pressure, mannitol was intravenously administered $(0.5-1.0 \mathrm{~g} / \mathrm{kg})$ every $4-6 \mathrm{~h}$, together with intravenous dexamethasone $(0.5 \mathrm{mg} / \mathrm{kg})$ once daily. Gamma globulin was also intravenously administered ( $2 \mathrm{~g} / \mathrm{kg}$, over $2-3$ days) to all patients. Ribavirin (10 $\mathrm{mg} / \mathrm{kg}$ per day) was used as an antiviral therapy. Other treatment included amrinone [0.25$0.4 \mu \mathrm{g} /(\mathrm{kg} \cdot \mathrm{min})$ i.v.] or dobutamine for ventricular dysfunction, and dopamine for hypotension. In addition, an ice bag was applied to the head of each patient to reduce brain temperature, and full parenteral nutrition was provided to all patients before they were able to take oral food or fluid.

\section{Data Collection}

Patients' demographic data, clinical symptoms, major complications and results of laboratory tests, such as white blood cell count, blood sugar and lactic acid, chest X-ray and viral pathology were collected. The data on mechanical ventilation such as duration of the ventilation, complications of the ventilation and the outcomes of the treatment were also registered.

Statistical Analysis

This is largely a descriptive study. Data are presented as means \pm SD or percentages. No statistical analysis was performed.

\section{Results}

\section{General Findings}

The general characteristics of the patients are shown in table 1 . The majority $(\mathrm{n}=125,85 \%)$ of the patients were under 3 years old, and 102 (69.4\%) were boys. Skin rashes were present in all patients. The most common locations of skin rashes were hands, feet and oral mucosa (fig. 1). However, in more than half of the patients $(\mathrm{n}=78,53.1 \%)$ 

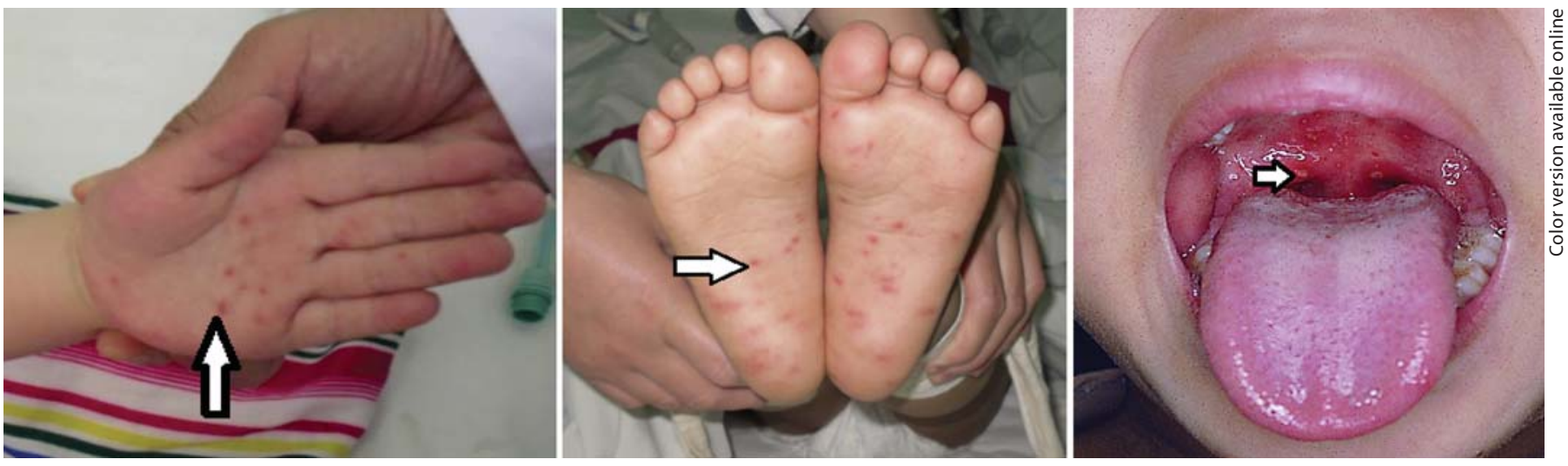

Fig. 1. Skin rash on hands and feet and mouth ulcers (arrows) of HFMD.

rashes were also found in the hip areas. All patients had a fever of $>38^{\circ} \mathrm{C}$, and more than half $(\mathrm{n}=80,54.4 \%)$ had high fever of $39^{\circ} \mathrm{C}$ or above. The main symptom of the central nervous system was lethargy, and 6 patients were unconscious at the time of admission. The majority of the patients had a rapid respiration rate $(\mathrm{n}=112,76.2 \%)$ and tachycardia $(\mathrm{n}=134,91.2 \%)$, but $21(14.3 \%)$ had slow and shallow respiration. Twenty patients (13.9\%) showed piebald skin, a sign of poor peripheral circulation.

As shown in table 2, increases in white blood cell count occurred in $44(30 \%)$ of the patients and leukopenia was found in $6(4.1 \%)$. The majority $(\mathrm{n}=127,86.4 \%)$ of the patients had hyperglycemia but hypoglycemia was also found in 5 (3.4\%). In $130(88.4 \%)$ of the patients the plasma lactic acid level was increased at admission.

\section{Chest X-Ray and Virology Examination}

The X-ray findings are shown in table 2. Increased markings were found in more than half $(\mathrm{n}=76,51.7 \%)$ of patients, and consolidations in both lungs were identified in nearly a third $(\mathrm{n}=44,29.9 \%)$. Positive virology tests were found in 113 (76.9\%) of the patients (table 2).

\section{Mechanical Ventilation and Pharmacological Therapies}

The mean interval between onset of fever to the beginning of ventilation was $3.1 \pm 1.0$ days (range, $1-4$ ). The mean duration of mechanical ventilation was $61.2 \pm$ $12.8 \mathrm{~h}$ (range 40-96). The medications used are listed in table 3. Mannitol, dexamethasone, gamma globulin and ribavirin were administered to all patients. Amrinone was used in $32(21.8 \%)$ of patients and dopamine, dobutamine were used in more than half $(51.0-100 \%)$ of the patients.
Table 1. General characteristics of the 147 patients

\begin{tabular}{lc}
\hline Indices & Values \\
\hline Age, months & $19.5 \pm 8.3(3$ months to 5 years) \\
Age $<3$ years & $125(85.0 \%)$ \\
Male & $102(69.4 \%)$ \\
Fever & $147(100 \%)$ \\
$\geq 39^{\circ} \mathrm{C}$ & $80(54.4 \%)$ \\
$38-38.9^{\circ} \mathrm{C}$ & $67(45.6 \%)$ \\
Skin rashes & $147(100 \%)$ \\
Hands & $147(100 \%)$ \\
Feet & $109(74.1 \%)$ \\
Oral & $119(80.1 \%)$ \\
Hips & $78(53.1 \%)$ \\
Central nervous system & \\
Lethargy & $124(84.4 \%)$ \\
Myoclonic jerks & $76(51.7 \%)$ \\
Drowsiness & $34(23.1 \%)$ \\
Unconsciousness & $6(4.1 \%)$ \\
Respiratory system & \\
Tachypnea & $112(76.2 \%)$ \\
Bradypnea & $21(14.3 \%)$ \\
Irregular respiration & $14(9.5 \%)$ \\
Cardiovascular system & \\
Tachycardia & $134(91.2 \%)$ \\
Bradycardia & $13(8.8 \%)$ \\
Hypertension & $23(15.5 \%)$ \\
Hypotension & $5(3.4 \%)$ \\
Others & \\
Cold extremities & $20(13.6 \%)$ \\
Piebald skin & \\
&
\end{tabular}

\section{Outcomes}

Of the 147 patients, 3 (2.0\%) died during the hospitalization due to progressive pulmonary edema and respiratory dysfunction. The other 144 patients recovered fully and were discharged from the hospital. The mean hospi- 
Table 2. Laboratory examination results

\begin{tabular}{lcc}
\hline Indices & $\begin{array}{c}\text { Admission } \\
(\mathrm{n}=147)\end{array}$ & $\begin{array}{l}\text { Discharge } \\
(\mathrm{n}=144)\end{array}$ \\
\hline White blood cell count & & \\
$>15 \times 10^{9} / 1$ & $44(30.0 \%)$ & $3(2.1 \%)$ \\
$\quad<4 \times 10^{9} / 1$ & $6(4.1 \%)$ & $0(0 \%)$ \\
Fasting blood sugar & $54(36.7 \%)$ & $1(0.7 \%)$ \\
$\quad 6.1-9$ mmol/l & $73(49.7 \%)$ & $2(1.4 \%)$ \\
$>9$ mmol/l & $5(3.4 \%)$ & $0(0 \%)$ \\
Hypoglycemic & $15(10.2 \%)$ & $144(100.0 \%)$ \\
$\quad$ Normal range & $0.5-2.2 \mathrm{mmol} / 1$ & \\
Plasma lactic acid & $130(88.4 \%)$ & $0(0 \%)$ \\
$\quad$ Increased & $27(18.4 \%)$ & $141(97.9 \%)$ \\
Chest X-ray & $44(29.9 \%)$ & $0(0 \%)$ \\
$\quad$ Normal & $76(51.7 \%)$ & $3(2.1 \%)$ \\
$\quad$ Consolidation & $113(76.9 \%)$ & $3(2.1 \%)$ \\
$\quad$ Increased markings & $51(34.7 \%)$ & $1(0.7 \%)$ \\
Virology study & $62(42.2 \%)$ & $2(1.4 \%)$ \\
$\quad$ Throat swab positive EV-71 & \\
Rectal swab positive EV-71 &
\end{tabular}

Table 3. Use of medications

\begin{tabular}{lccl}
\hline Medication & Patients & $\begin{array}{l}\text { Duration of } \\
\text { treatment, } \\
\text { days }\end{array}$ & Daily dose \\
\hline Mannitol & $147(100 \%)$ & $5-7$ & $2-6 \mathrm{~g} / \mathrm{kg}$ \\
Dexamethasone & $147(100 \%)$ & $3-5$ & $0.3-0.5 \mathrm{mg} / \mathrm{kg}$ \\
Gamma globulin & $147(100 \%)$ & 2 & $1 \mathrm{~g} / \mathrm{kg}$ \\
Ribavirin & $147(100 \%)$ & $10-14$ & $10 \mathrm{mg} / \mathrm{kg}$ \\
Amrinone & $32(21.8 \%)$ & $2-3$ & $0.5 \mathrm{mg} / \mathrm{kg}$ \\
Dobutamine & $75(51.0 \%)$ & $2-3$ & $7-14 \mathrm{mg} / \mathrm{kg}$ \\
Dopamine & $86(58.5 \%)$ & $2-3$ & $7-14 \mathrm{mg} / \mathrm{kg}$ \\
\hline
\end{tabular}

tal stay was $14.2 \pm 1.6$ days (range, $12-17$ ). Body temperature, blood pressure, heart rate and respiration were within normal range before the discharge. None of the patients had skin rashes at the end of the treatment. Fasting blood sugar levels, blood lactic acid levels, chest X-ray and virology tests were normal in the majority of the patients before discharge (table 2).

\section{Discussion}

The major findings of the present study included central nervous system symptoms, skin rashes and a fever of $\geq 38^{\circ} \mathrm{C}$. Lethargy and myoclonic jerks were the most common signs of central nervous system involvement. Other symptoms were increased markings or consolidation on chest X-ray, and hyperglycemia and elevated blood lactic acid levels. These symptoms had been reported in other studies $[5,8,12,13]$. Myoclonic jerks in children with HFMD are considered an early indicator of neurological involvement, particularly in the brainstem [14]. Brainstem encephalitis-associated neurogenic pulmonary edema can develop very rapidly in children, and acute cardiorespiratory failure and shock may soon follow [1]. The acute-phase mortality rate in patients with signs of cardiopulmonary failure can be as high as $33 \%$ [15]. Even if neurogenic pulmonary edema is managed successfully in the pediatric intensive care unit, patients may be left with significant debilitating morbidity [16].

Management of these patients in an intensive care unit with mechanical ventilation is critically important. In our hospital, after lessons learned from several largescale outbreaks in previous years, we developed a set of criteria to help clinicians decide when to commence mechanical ventilation before detecting significant pulmonary edema. These criteria include signs of central nervous system involvement, such as lethargy, myoclonic jerks or drowsiness, unstable hemodynamics (tachycardia, hyper- or hypotension, cold extremities or piebald skins), or changes in normal respiratory rate or rhythm. In addition, there must be elevation of blood lactic acid levels or abnormal fasting blood sugar tests, as these changes may suggest poor peripheral perfusion or more severe disease status. Using these criteria, mechanical ventilation was applied to all 147 patients for an average of $61.2 \mathrm{~h}$. This approach and other supportive pharmacotherapies are associated with a full recovery in the majority of patients with little complications from the mechanical ventilation or HFMD.

All our patients were treated with intravenous gamma globulin to immunomodulate the inflammatory process and provide some anti-inflammatory action. The actual efficacy of this immunoglobulin treatment, however, is uncertain and further randomized clinical trials are required [1]. Ribaviron was also used in all patients as an antiviral drug, as a previous study showed that it reduces viral replication and mortality after enterovirus EV71 infection [17]. Dobutamine was used in 75 (51\%) of the patients for the treatment of ventricular dysfunction. In a smaller proportion of patients $(32,21.8 \%)$, amrinone, a cyclic nucleotide phosphodiesterase inhibitor, was used in the treatment of congestive heart failure. Although the effect of amrinone in treating heart failure following HFMD has not been prospectively studied, a retrospec- 
tive analysis of a similar drug, milrinone, showed that in children with EV71-induced pulmonary edema milrinone treatment was associated with a reduced tachycardia and lower mortality [18].

The long-term outcomes of our patients are not clear; a longitudinal study will be necessary. Other studies have shown that approximately 1 in 5 patients with severe neurological disease have complications, such as focal limb weakness and atrophy [1]. Cerebellar disorders, such as cranial neuropathies, myoclonus, tremor, and ataxia, may develop in about $10 \%$ of patients after moderately severe brainstem encephalitis [1]. In the 144 surviving patients in the present study, neurological examination done before hospital discharge did not show abnormalities.

\section{Conclusion}

The majority of patients with severe HFMD from this inland Chinese community were less than 3 years old and nearly $70 \%$ were boys. All patients had high fever and skin rashes, and more than $80 \%$ had elevated fasting blood sugar and lactic acid levels. Mechanical ventilation and supportive pharmacological management in a designated intensive care unit were associated with a good clinical outcome, resulting in full recovery in most of the patients.

\section{References}

$>1$ Ooi MH, Wong SC, Lewthwaite P, Cardosa MJ, Solomon T: Clinical features, diagnosis, and management of enterovirus 71. Lancet Neurol 2010;9:1097-1105.

-2 Chan L, Parashar U, Lye M, Ong FG, Zaki SR, Alexander JP, Ho KK, Han LL, Pallansch MA, Suleiman AB, Jegathesan M, Anderson LJ: Deaths of children during an outbreak of hand, foot, and mouth disease in Sarawak, Malaysia: clinical and pathological characteristics of the disease. Clin Infect Dis 2000; 31:678-683.

$>3$ Chang LY, King CC, Hsu KH, Ning HC, Tsao KC, Li CC, Huang YC, Shih SR, Chiou ST, Chen PY, Chang HJ, Lin TY: Risk factors of enterovirus 71 infection and associated hand, foot, and mouth disease/herpangina in children during an epidemic in Taiwan. Pediatrics 2002;109:e88.

$\checkmark 4$ Chen SC, Chang HL, Yan TR, Cheng YT, Chen KT: An eight-year study of epidemiologic features of enterovirus 71 infection in Taiwan. Am J Trop Med Hyg 2007;77:188-191.

5 Zhang Y, Zhu Z, Yang W, Ren J, Tan X, Wang Y, Mao N, Xu S, Zhu S, Cui A, Zhang Y, Yan D, Li Q, Dong X, Zhang J, Zhao Y, Wan J, Feng Z, Sun J, Wang S, Li D, Xu W: An emerging recombinant human enterovirus 71 responsible for the 2008 outbreak of hand foot and mouth disease in Fuyang city of China. Virol J 2010;7:94.
6 Mirand A, Schuffenecker I, Henquell C, Billaud G, Jugie G, Falcon D, Mahul A, Archimbaud C, Terletskaia-Ladwig E, Diedrich S, Huemer HP, Enders M, Lina B, Peigue-Lafeuille H, Bailly JL: Phylogenetic evidence for a recent spread of two populations of human enterovirus 71 in European countries. J General Virol 2010;91:2263-2277.

$>7$ Blomqvist S, Klemola P, Kaijalainen S, Paananen A, Simonen ML, Vuorinen T, Roivainen M: Co-circulation of coxsackieviruses A6 and A10 in hand, foot and mouth disease outbreak in Finland. J Clin Virol 2010;48:49-54.

$>$ Ooi MH, Wong SC, Mohan A, Podin Y, Perera D, Clear D, del Sel S, Chieng CH, Tio PH, Cardosa MJ, Solomon T: Identification and validation of clinical predictors for the risk of neurological involvement in children with hand, foot, and mouth disease in Sarawak. BMC Infect Dis 2009;9:3.

9 Chinese Ministry of Health: Prevention and control guidelines for hand, foot and mouth disease. http://www.gov.cn/gzdt/2008-05/ 03/content_960347.htm (accessed on 6 January 2011).

10 Chinese Ministry of Health: Diagnosis and treatment guidelines for human enterovirus EV71. http://disease.39.net/ek/crxjb/085/8/ 409737.html (accessed on 6 January 2011).

11 http://www.emedicinehealth.com/pediatric_vital_signs/article_em.htm (accessed on 2 June 2011).

12 Ooi MH, Wong SC, Podin Y, Akin W, del Sel $\mathrm{S}$, Mohan A, Chieng CH, Perera D, Clear D, Wong D, Blake E, Cardosa J, Solomon T: Human enterovirus 71 disease in Sarawak, Malaysia: a prospective clinical, virological, and molecular epidemiological study. Clin Infect Dis 2007;44:646-656.
13 Huang CC, Liu CC, Chang YC, Chen CY, Wang ST, Yeh TF: Neurologic complications in children with enterovirus 71 infection. $\mathrm{N}$ Engl J Med 1999;341:936-942.

14 Lu HK, Lin TY, Hsia SH, Chiu CH, Huang YC, Tsao KC, Chang LY: Prognostic implications of myoclonic jerk in children with enterovirus infection. J Microbiol Immunol Infect 2004;37:82-87.

15 Chang LY, Hsia SH, Wu CT, Huang YC, Lin KL, Fang TY, Lin TY: Outcome of enterovirus 71 infections with or without stage-based management: 1998 to 2002. Pediatr Infect Dis J 2004;23:327-331.

16 Prager P, Nolan M, Andrews IP, Williams GD: Neurogenic pulmonary edema in enterovirus 71 encephalitis is not uniformly fatal but causes severe morbidity in survivors. Pediatr Crit Care Med 2003;4:377-381.

17 Li ZH, Li CM, Ling P, Shen FH, Chen SH, Liu $\mathrm{CC}, \mathrm{Yu} \mathrm{CK}$, Chen SH: Ribavirin reduces mortality in enterovirus 71-infected mice by decreasing viral replication. J Infect Dis 2008;197:854-857.

18 Wang SM, Lei HY, Huang MC, Wu JM, Chen CT, Wang JN, Wang JR, Liu CC: Therapeutic efficacy of milrinone in the management of enterovirus 71-induced pulmonary edema. Pediatr Pulmonol 2005;39:219-223. 